F. Reprod. Fert. (1970) 22, 177-179

\title{
FLUORESCENT STAINING OF THE Y CHROMOSOME IN MEIOTIC STAGES OF THE HUMAN MALE
}

\author{
P. L. PEARSON AND M. BOBROW \\ M.R.C. Population Genetics Unit, \\ Old Road, Headington, Oxford
}

(Received 2nd April 1970)

It has been previously reported that the distal half of the long arm of the human $\mathrm{Y}$ chromosome shows a differential affinity for fluorescent acridine derivatives (Zech, 1969; Pearson, Bobrow \& Vosa, 1970). By the use of this staining reaction, the $\mathrm{Y}$ chromosome can be detected in interphase nuclei of lymphocytes, cultured skin fibroblasts and buccal mucosal cells. This technique has also been used to demonstrate that the $\mathrm{X}$ chromosome pairs with the short arm of the $\mathrm{Y}$ in first meiotic prophase (Pearson \& Bobrow, unpublished observation). This paper describes the appearance of the $\mathrm{Y}$ chromosome in the different stages of spermatogenesis.

Cytological preparations for the examination of meiotic cells were prepared from testicular tissue of three normal adult males by the method of Evans, Brecon \& Ford (1964). Some material was prepared without hypotonic treatment, particularly for examination of pachytene. Slides were stained for $3 \mathrm{~min}$ in a $0.5 \%$ aqueous solution of quinacrine dihydrochloride (Atebrin, G. Gurr), rinsed briefly in running tap water and then in distilled water, allowed to dry and then mounted in buffer $\mathrm{pH} 5 \cdot 5$. The specimens were examined on a Leitz Ortholux microscope with an Opak vertical illuminator, an HBO 200 light source with a $5 \mathrm{~mm}$ BG 12 excitor filter and a $510 \mathrm{~nm}$ barrier filter.

The $\mathrm{Y}$ chromosome can be positively identified in the great majority of lymphocyte mitotic metaphases, although about 10 to $20 \%$ of cells fail to show the typical staining reaction. The other chromosomal regions which commonly fluoresce are a small area next to the centromere of No. 3, and the satellites of one pair of $\mathrm{D}$ group chromosomes. In spermatogonial metaphases, however, the $\mathrm{Y}$ chromosome showed positive fluorescence in fewer than $5 \%$ of cells. The majority of nuclei showed no differential fluorescence (cf. Pl. 1, Figs. 1 and 2). In those cells which did exhibit a fluorescent $\mathrm{Y}$ chromosome, the intensity of fluorescence was less than that usually seen in other material. Interphase nuclei of spermatogonia did not show the fluorescent body seen in other interphase nuclei.

In all other stages of spermatogenesis, the $\mathrm{Y}$ chromosome fluoresced brightly. Plate 1, Figs. 3 to 6 show a succession of stages through first meiotic prophase up to and including pachytene. The fluorescent body is clearly visible in the great majority of cells at all stages. It can be seen to be associated with the 'sex vesicle', which is believed to contain the $\mathrm{X}$ and $\mathrm{Y}$ chromosomes. Smaller 
fluorescent areas, presumably representing the paracentric region of No. 3 , can be seen in some cells (Pl. 1, Figs. 5 and 6).

At diakinesis, the sex bivalent regularly shows a terminal fluorescent area (PI. 1, Fig. 7). Small fluorescent areas centrally situated on a large bivalent, presumably the No. 3 pair, are also shown in this figure. Where the sex chromosomes are not associated, the fluorescent area of the $\mathrm{Y}$ chromosome can be seen to extend for about half of its length, much as in mitotic preparations (Pl. 2, Fig. 8). The fact that the fluorescent area is always at the extreme end of the sex bivalent has been adduced as evidence that it is the short arm of the Y chromosome which pairs with the $\mathrm{X}$ chromosome (Pearson \& Bobrow, unpublished observation). Plate 2, Fig. 10 shows an abnormal diakinesis. Despite the poor quality of the cell, a single structure with two large fluorescent areas can be seen. This is tentatively interpreted as a $\mathrm{Y}$ bivalent, the two $\mathrm{Y}$ chromosomes being present as a result of non-disjunction at a previous mitotic division.

The fluorescent area can be seen in some second meiotic metaphases ( $\mathrm{Pl} .2$, Fig. 9), spermatids (Pl. 2, Figs. 11 to 13) and mature spermatozoa (Pl. 2, Fig. 14). The size of the fluorescent body in these highly condensed nuclei is comparable to that seen in somatic interphase nuclei. Spermatids may sometimes be seen lying in pairs, each pair presumably representing the products of a second meiotic division. In such cases, the members of the pair are almost invariably concordant for the presence or absence of the fluorescent body (Pl. 2, Fig. 11). In mature spermatozoa (Pl. 2, Fig. 14), the fluorescent body tends to be located at the acrosomal end of the nucleus, although many exceptions to this have been seen.

Theoretically, one would expect $50 \%$ of spermatozoa to contain a Y chromosome, although for technical reasons the actual proportion of cells showing a fluorescent body is unlikely to reach this level. Of 1420 spermatids scored from areas showing technically good staining, 733 showed no fluorescent body and

\section{EXPLANATION OF PLATES}

PLATE 1

FIG. 1. Spermatogonial metaphase; no fluorescent chromatin.

FIG. 2. Spermatogonial metaphase showing fluorescent $Y$ chromosome.

Figs. 3 to 6 . First meiotic prophase showing fluorescent area of $Y$ chromosome associated with sex vesicle (large arrow) and fluorescent area of No. 3 chromosome (small arrow). FIG. 7. Diakinesis. $\mathrm{X}-\mathrm{Y}$ bivalent showing terminal fluorescence (large arrow) and chromosome No. 3 showing small fluorescent areas (small arrows).

\section{PLATE 2}

Fic. 8. Diakinesis. Separate $\mathrm{X}$ and $\mathrm{Y}$ chromosomes. $\mathrm{Y}$ chromosome showing differential fluorescence.

FIG. 9. Second meiotic metaphase, showing fluorescent $\mathrm{Y}$ chromosome.

Fic. 10. Abnormal diakinesis showing presumptive $Y$ bivalent.

FIG. 11. Pairs of spermatids with and without fluorescent ' $Y$ bodies'.

FIG. 12. Polyploid spermatid with two 'Y bodies'.

FIG. 13. Normal sized spermatid with two 'Y bodies'.

Fig. 14. Mature spermatozoa. 
11. 1!
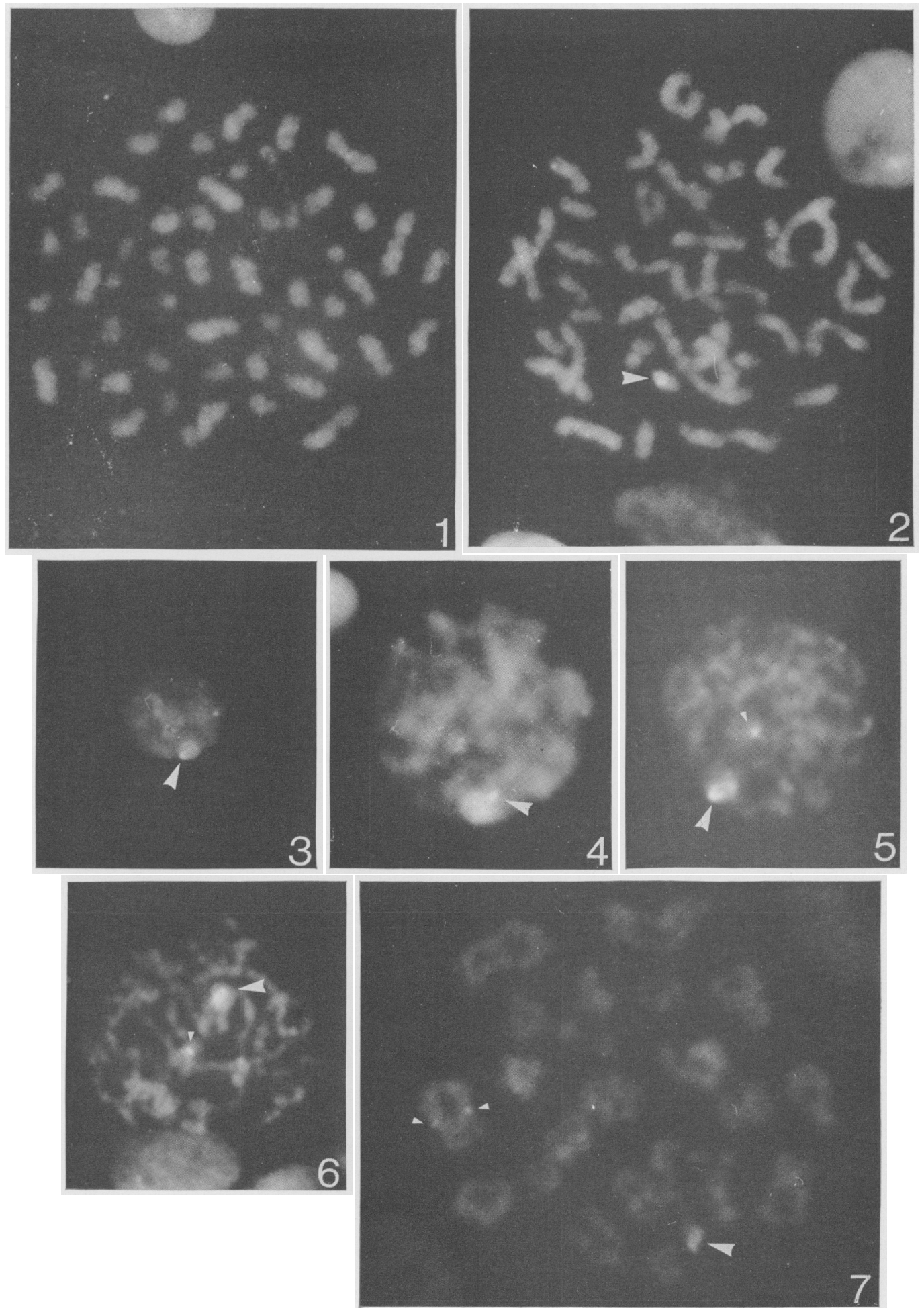
|P. II
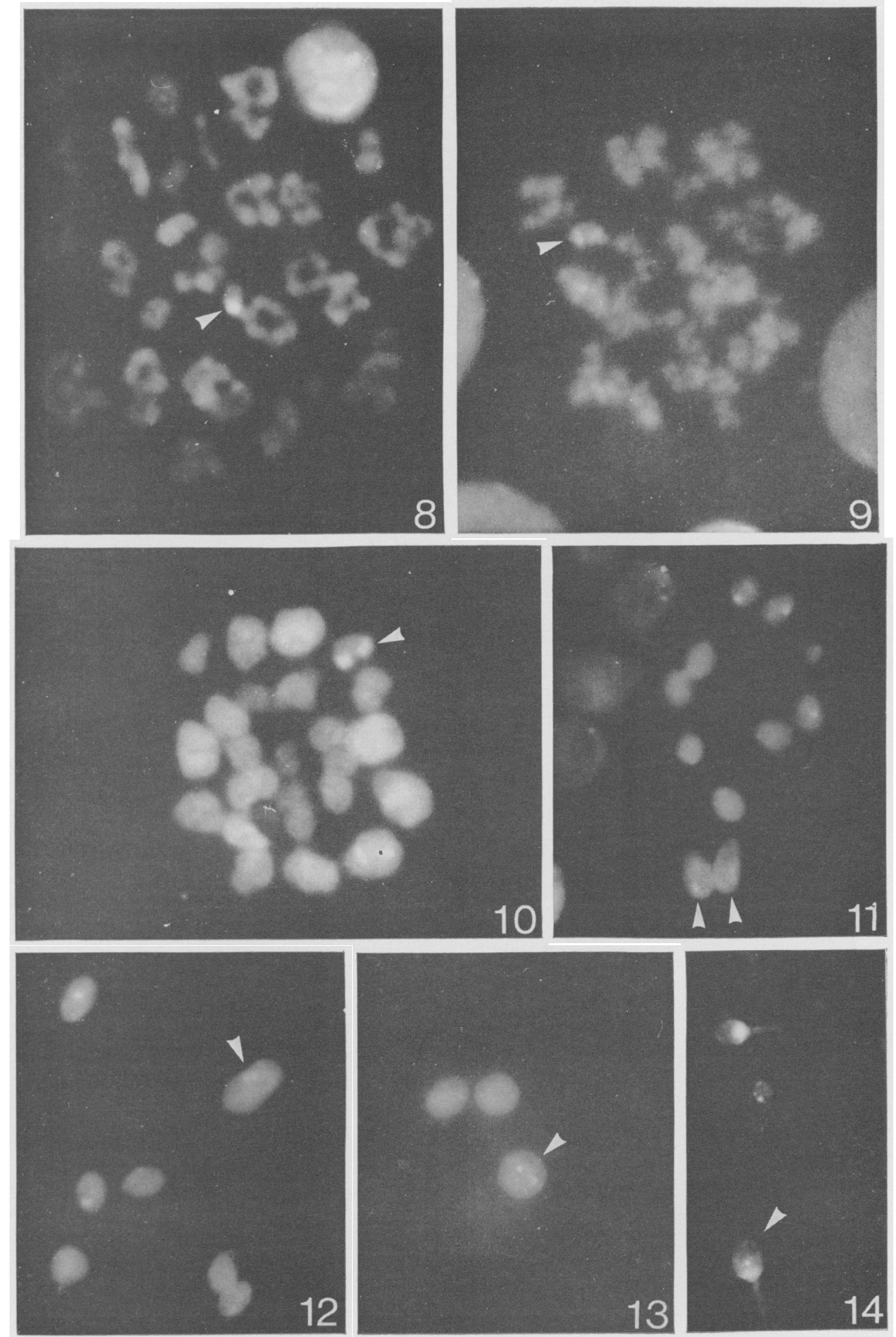

10
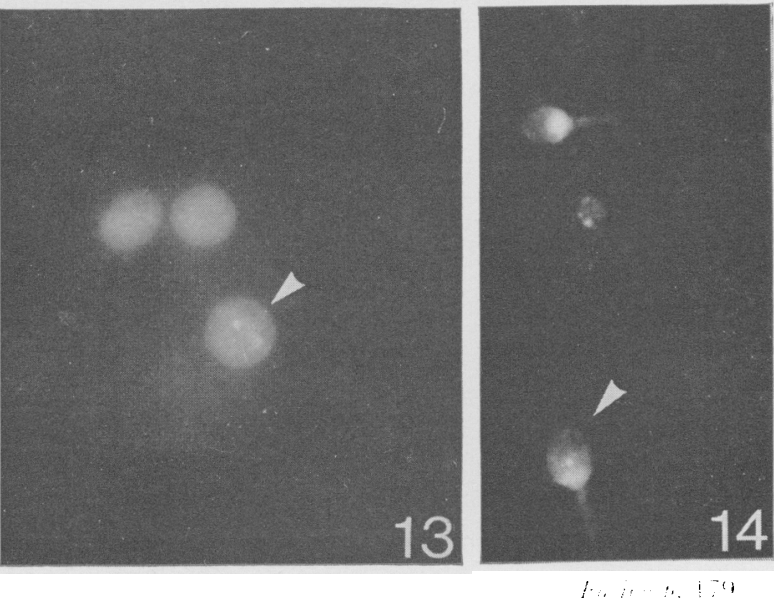

Downloaded from Bioscientifica.com at $04 / 26 / 2023$ 03:23:26AM 
666 contained a single fluorescent body. The remaining twenty-one cells $(1.4 \%)$ had two fluorescent bodies each. An example of such a spermatid is shown in Pl. 2, Fig. 13. Giant forms, presumably polyploid, have also been seen with two fluorescent bodies (Pl. 2, Fig. 12) but the twenty-one cells referred to above did not include any abnormally large forms. This proportion of gametes with two $\mathrm{Y}$ chromosomes cannot be immediately reconciled with what is known of the birth incidence of XYY males, but much more evidence is needed before the cause of this discrepancy can be discussed.

\section{REFERENGES}

Evans, E. P., Brecon, G. \& Ford, C. E. (1964) An air drying method for meiotic preparations from mammalian testes. Cytogenetics, 3, 289.

Pearson, P. L., Bobrow, M. \& Vosa, C. G. (1970) Technique for identifying Y chromosomes in human interphase nuclei. Nature, Lond. (in press).

ZECH, L. (1969) Investigation of metaphase chromosomes with DNA-binding fluorochromes. Expl Cell Res. 58, 463. 